Laser Chem. 1987, Vol. 7, pp. 95-107

Photocopying permitted by license only

(C) 1987 Harwood Academic Publishers GmbH

Printed in the United Kingdom

\title{
Photodissociation of Cadmium Diiodide
}

\author{
KAZUO KASATANI, KOJI MORI, MASAHIRO KAWASAKI and \\ HIROYASU SATO
}

Chemistry Department of Resources, Faculty of Engineering, Mi'e University, Tsu 514, Japan

\begin{abstract}
Photodissociation of cadmium diiodide was studied. The nascent vibrational distribution of $\operatorname{CdI}\left(X^{2} \Sigma\right)$ on the photodissociation of $\mathrm{CdI}_{2}$ at $308 \mathrm{~nm}$ was determined by the laser-induced fluorescence (LIF) technique. The temporal variation in the density of $\operatorname{CdI}\left(X^{2} \Sigma\right)$ radicals was monitored and it was shown that second-order recombination reactions were important under our experimental conditions. Both the ground and the highly excited states of cadmium atoms were generated on photodissociation of $\mathrm{CdI}_{2}$. The multiphoton absorption process for the production of highly excited Cd atoms is discussed.
\end{abstract}

KEY WORDS: Photodissociation of cadmium diiodide; LIF; second order reachons; MP absorptions; excited state Cd atoms.

\section{INTRODUCTION}

The photodissociation of many of the triatomic group IIB metal halides continues to attract attention because it provides an efficient method for pumping of laser transitions in atomic and molecular species ${ }^{1-5}$. Concerning cadmium halides, lasing has been reported for $\operatorname{CdI}\left(B^{2} \Sigma^{+}\right)$and $\operatorname{Cd}\left(5^{1} D_{2}\right.$ and $\left.6^{3} S_{1}\right)$ by excimer laser photodissociation of $\mathrm{CdI}_{2}$ molecules. Dissociative excitation of mercury dihalide molecules in a fast transverse discharge ${ }^{6,7}$ and relativistic electron beam irradiation of gas mixture were also attempted ${ }^{8-10}$. The first two pumping methods have an advantage over the third in that they involve a cyclic production scheme for the excited species, i.e. the $\mathbf{M X}_{2}$ molecules are regenerated efficiently after lasing. 
In the present paper, the photodissociation of a linear metal halide, $\mathrm{CdI}_{2}$, with a 308-nm XeCl laser or a 337- $\mathrm{nm} \mathrm{N}_{2}$ laser is studied in order to know the primary process and the reaction dynamics of the photodissociation. Possible dissociation processes with the one-photon energy are given as $^{11}$ :

$$
\begin{aligned}
\mathrm{CdI}_{2}\left({ }^{1} \Sigma\right) \longrightarrow \mathrm{CdI}\left(X^{2} \Sigma\right)+\mathrm{I}\left({ }^{2} P_{3 / 2}\right) & E_{0}=239.8 \mathrm{~kJ} \mathrm{~mol}^{-1} \\
\longrightarrow \mathrm{CdI}\left(X^{2} \Sigma\right)+\mathrm{I}\left({ }^{2} P_{1 / 2}\right) & E_{0}=330.7 \mathrm{~kJ} \mathrm{~mol}^{-1} \\
\mathrm{Cd}\left({ }^{1} S\right)+2 \mathrm{I}\left({ }^{2} P_{3 / 2}\right) & E_{0}=389.6 \mathrm{~kJ} \mathrm{~mol}^{-1}
\end{aligned}
$$

If the dissociation follows Eqn (1), $\operatorname{CdI}\left(X^{2} \Sigma\right)$ produced must be excited to high vibrational levels. In the present paper, a spectroscopic study on CdI $C-X, D-X$ transitions, a kinetic study on CdI disappearance, and observation of atomic lines of $\mathrm{Cd}$ metal by multiphoton dissociation of $\mathrm{CdI}_{2}$ are presented.

\section{EXPERIMENTAL}

The optical cells used in these experiments were made of quartz, $40 \mathrm{~mm}$ in length, $25 \mathrm{~mm}$ in diameter, and had a sidearm. After several milligrams of $\mathrm{CdI}_{2}$ (Wako) were introduced into each cell, it was evacuated to $<1 \mathrm{mTorr}$ and sealed under vacuum. The cell was placed in an oven, and chromel-alumel thermocouples were used to monitor the temperature of the oven and the separately heated sidearm. The vapor pressure of the metal halide in the cell was estimated from the temperature of the sidearm, which was lower than that of the oven.

The experimental setup for the measurement of the laser-induced fluorescence (LIF) spectrum is given in Figure 1. A pulsed $\mathrm{XeCl}$ laser (Lambda Physik EMG 103MSC, $\sim 100 \mathrm{~mJ} /$ pulse) was used as a photolysis source and as a pump laser of a dye laser (Lambda Physik LF2002) at the same time. After a delay of $10 \mathrm{~ns}$, the $\operatorname{CdI}\left(X^{2} \Sigma\right)$ radical produced was excited by the dye laser. The laser-induced fluorescence was detected by a photomultiplier (Hamamatsu 1P28) through a $25-\mathrm{cm}$ monochromator (Nikon P-250 or G-250). The signal was fed to a Boxcar integrator (PAR 162/164) through a preamplifier (PAR 115) and was recorded by a strip chart recorder.

In the measurement of the temporal variation in the density of $\operatorname{CdI}\left(X^{2} \Sigma\right)$ radicals, a homemade $\mathrm{N}_{2}$ laser $(\sim 1 \mathrm{~mJ} /$ pulse $)$ was used to 


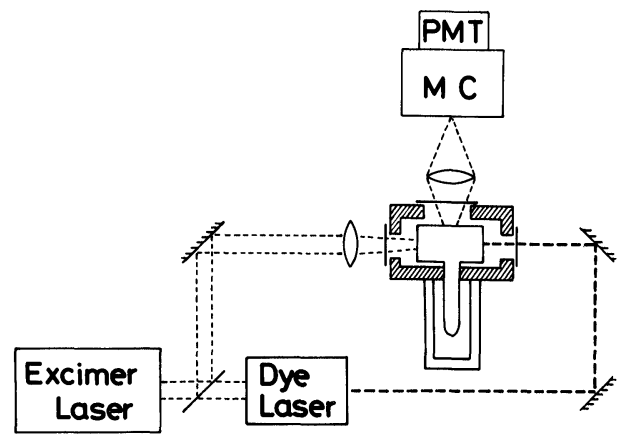

Figure 1 Experimental setup for the measurement of the LIF spectra. About 30 percent of the output of the $308-\mathrm{nm} \mathrm{XeCl}$ laser was used to dissociate $\mathrm{CdI}_{2}$, and the rest was used to pump the dye laser.

dissociate $\mathrm{CdI}_{2}$. An $\mathrm{XeCl}$ laser-pumped dye laser $(0.1 \mathrm{~mJ} /$ pulse $)$ was timed to probe the sample at selected delay times following the dissociation pulse. Intensity measurements of LIF from $\operatorname{CdI}\left(C^{2} \Pi_{1 / 2}\right.$, $v^{\prime}=0 \rightarrow X^{2} \Sigma, v^{\prime \prime}=0$ or 1 ) band gave a measure of the instantaneous density of CdI ground-state radicals.

The formation and decay of $\mathrm{Cd}$ atoms generated in its ground state in the 308-nm laser photolysis of $\mathrm{CdI}_{2}$ were monitored by absorption using a cadmium hollow-cathode lamp. The light of the cadmium lamp was defocused to cover the whole photolysis cell in order for $\mathrm{Cd}$ atoms not to diffuse out of the viewing region. The laser light was also defocused and the output from a photomultiplier was digitized by a transient recorder. Typically, 1000 separate laser-initiated photolysis runs were accumulated in a signal averager.

The emission from the electronically excited $\mathrm{Cd}$ atoms was measured by the monochromator and a photomultiplier (Hamamatsu R928).

\section{RESULTS AND DISCUSSION}

\section{LIF studies of Cdl radical}

\section{Potential curves of $C d I$ radical}

Figures 2(a) and (b) show the LIF emission spectra from the $v^{\prime}=0$ states of the $C^{2} \Pi_{1 / 2}$ and $D^{2} \Pi_{3 / 2}$ states, respectively. From the relative intensity we can obtain the Franck-Condon factors as tabulated in 


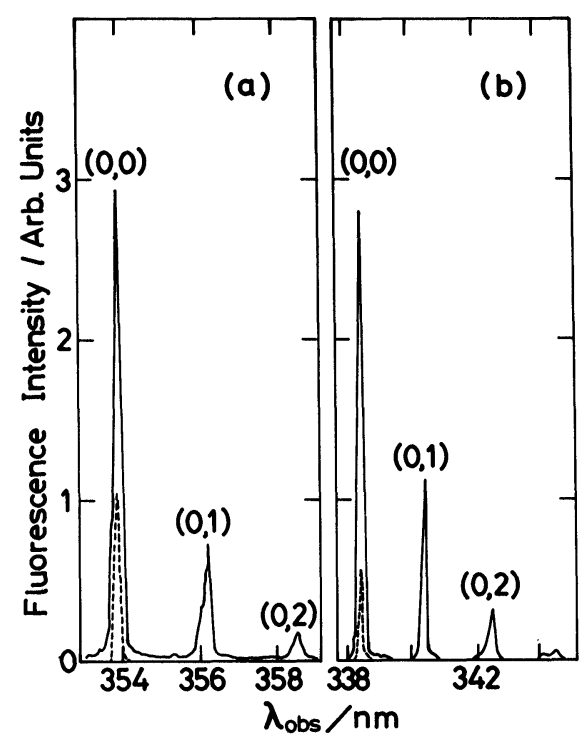

Figure 2 LIF spectra of CdI radical. (a) $\lambda_{\text {ex }}=354.03 \mathrm{~nm}\left(C^{2} \Pi_{1 / 2} \leftarrow X^{2} \Sigma(0,0)\right.$ band). (b) $\lambda_{\text {ex }}=338.40 \mathrm{~nm}\left(D^{2} \Pi_{3 / 2} \leftarrow X^{2} \Sigma(0,0)\right.$ band). Broken lines are with the photolysis laser off.

Table I. Since the Franck-Condon factors are sensitive to the relative location of two potential curves, we have calculated the FranckCondon factors with the value of $\Delta r_{\mathrm{e}}=r_{\mathrm{e}}^{\prime}-r_{\mathrm{e}}^{\prime \prime}$, the deviation of the equilibrium internuclear distance of each ${ }^{2} \Pi$ state from that of the ground state, as a parameter, and compared them with the experimental values. The potential curves of the ground, $C$, and $D$ states were approximated by Morse functions. The values of $\omega_{e}$ and $\omega_{e} x_{e}$ for these three states of the CdI radical are given by Huber and Herzberg ${ }^{12}$.

Table I Franck-Condon factors of $\mathrm{CdI} C^{2} \Pi_{1 / 2}-X^{2} \Sigma$ and $D^{2} \Pi_{3 / 2}-X^{2} \Sigma$ transitions.

\begin{tabular}{lllll}
\hline & & $C-X$ & & $D-X$ \\
\cline { 2 - 3 } \cline { 5 - 5 } & Observed & $\begin{array}{l}\text { Calculated } \\
\left(\Delta r_{\mathrm{e}}=-0.051 \AA\right)\end{array}$ & Observed & $\begin{array}{l}\text { Calculated } \\
\left(\Delta r_{\mathrm{e}}=-0.055 \AA\right)\end{array}$ \\
\hline$(0,0)$ & $0.65 \pm 0.02$ & 0.66 & $0.61 \pm 0.01$ & 0.60 \\
$(0,1)$ & $0.26 \pm 0.02$ & 0.26 & $0.29 \pm 0.02$ & 0.29 \\
$(0,2)$ & $0.08 \pm 0.01$ & 0.07 & $0.08 \pm 0.01$ & 0.08 \\
\hline
\end{tabular}


We found that the observed values of Franck-Condon factors were consistent with the calculated ones for $\Delta r_{\mathrm{e}}=-0.051 \AA$ for $C-X$ transition, and for $\Delta r_{\mathrm{e}}=-0.055 \AA$ for $D-X$ transition. These calculated values are also tabulated in Table $I$.

Since no band of the CdI radical has been thoroughly analyzed, $r_{\mathrm{e}}$ values of any states have not been known. The $B$ states of the group IIB metal-halide diatomic molecules were ionic in character. In the case of ${ }^{200} \mathrm{Hg}^{127} \mathrm{I}$ radical, $r_{\mathrm{e}}$ values are $2.18 \AA$ and $3.30 \AA$ for the $X$ and $B$ states, respectively ${ }^{13}$. Therefore, $r_{\mathrm{e}}$ of the $B$ state of the CdI radical must be larger than that of the ground state. Contrary to the $B$ state, $r_{\mathrm{e}}$ values of both the ${ }^{2} \Pi$ excited covalent states, $C^{2} \Pi_{1 / 2}$ and $D^{2} \Pi_{3 / 2}$, of the CdI radical are shorter than that of the ground state, because the absorption bands in $C-X$ and $D-X$ transitions are degraded towards the violet ${ }^{14}$. Our results of the Franck-Condon factors show that $r_{\mathrm{e}}$ varies little among the $X, C$, and $D$ states.

Vibrational population of the $C d I\left(X^{2} \Sigma\right)$ radicals photodissociated by an $\mathrm{XeCl}$ laser

Figure 3 shows the LIF excitation spectrum for the $D \leftarrow X$ transition of CdI radical obtained by observing the fluorescence of the $D \rightarrow X$

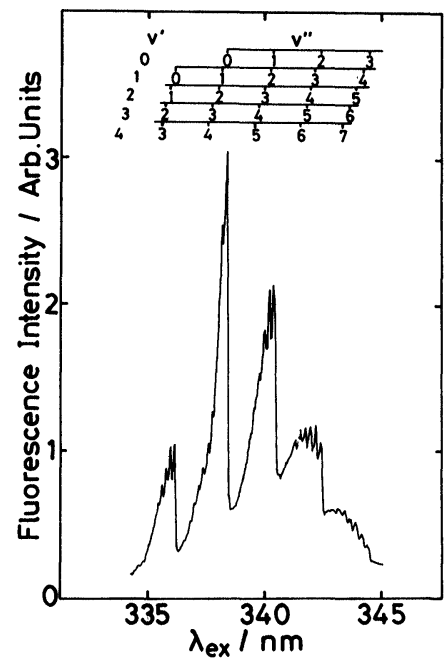

Figure 3 LIF excitation spectra for the $D \leftarrow X$ transition of CdI radical generated by photodissociation with $308-\mathrm{nm} \mathrm{XeCl}$ laser. $\lambda_{\text {obs }}=338.4 \mathrm{~nm}$. Resolution of the monochromator is $\sim 5 \mathrm{~nm}$. 


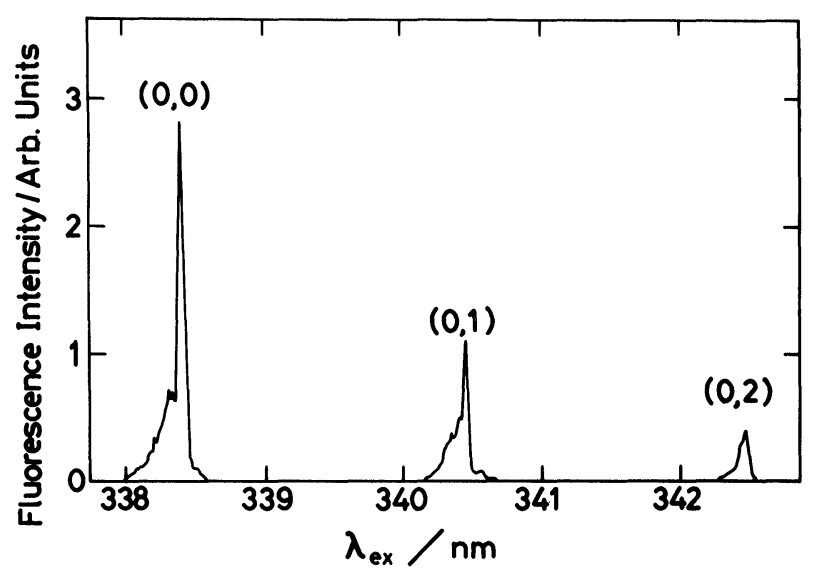

Figure 4 LIF excitation spectra for the $D \leftarrow X$ transition of the CdI radical. $\lambda_{\text {obs }}=338.4 \mathrm{~nm}\left(D^{2} \Pi_{3 / 2} \rightarrow X^{2} \Sigma(0,0)\right.$ band $)$.

transition with a broad resolution of the monochromator. This spectrum shows that several vibrational states are excited in the groundstate of CdI radical.

Figure 4 shows the LIF excitation spectra for the $D \leftarrow X$ transition obtained by observing the $D \rightarrow X(0,0)$ emission. From the relative intensity of each band in this spectrum and the Franck-Condon factors obtained above, the ratios of the vibrational population of the $\mathrm{CdI}$ ground state produced by photodissociation of $\mathrm{CdI}_{2}$ with a $308-\mathrm{nm}$ $\mathrm{XeCl}$ laser were determined to be $1.00: 0.85: 0.80$ for $v^{\prime \prime}=0,1,2$ levels, respectively.

We could determine the vibrational population for only the lowest three vibrational levels because the bands associated with higher vibrational levels are very much congested. Kawasaki et al. ${ }^{15}$ concluded that about half of the available energy was distributed as vibrational energy of CdI radicals in the photodissociation with $300-\mathrm{nm}$ laser radiation, based on the results of a photofragment time-of-flight (TOF) experiment. Therefore, higher vibrational levels $(v \geqslant 3)$ are expected to be occupied to a significant extent in our experimental conditions. Isotopically pure $\mathrm{CdI}_{2}$ molecule should be used in order to obtain the vibrational population for the vibrational levels with larger quantum numbers in order to avoid the spectral congestion. 


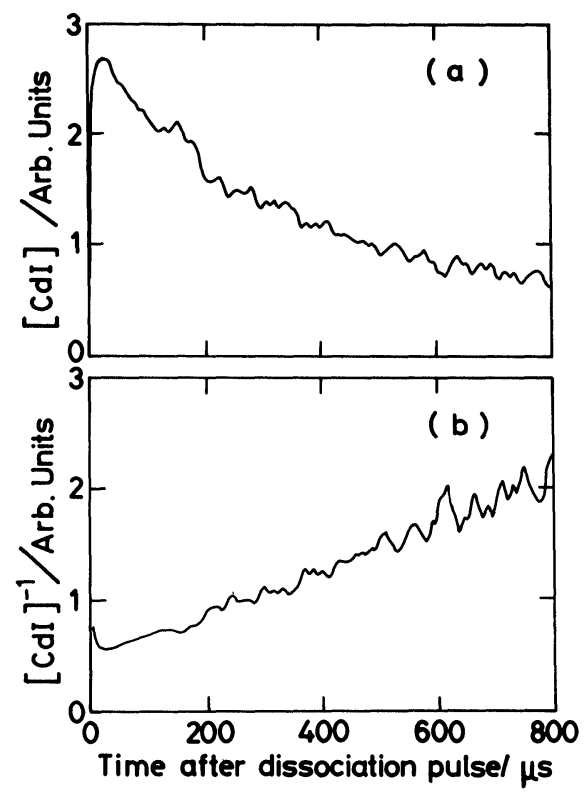

Figure 5 (a) An example of the temporal variation of the density of $\operatorname{CdI}\left(X^{2} \Sigma\right)$ radicals following the dissociation of $\mathrm{CdI}_{2}$ with a $337-\mathrm{nm} \mathrm{N} \mathrm{N}_{2}$ laser. $\lambda_{\text {ex }}=356.25 \mathrm{~nm}(C \leftarrow X(0,1)$ band). $\lambda_{\text {obs }}=354.03 \mathrm{~nm}(C \rightarrow X(0,0)$ band $)$. (b) The reciprocal plot of (a).

\section{Temporal behavior of $C d I\left(X^{2} \Sigma\right)$ radicals}

The temporal decay of $\mathrm{CdI}$ radical density was monitored as a function of time after the dissociation pulse. A nitrogen laser was used as a photolysis light source, and an $\mathrm{XeCl}$ laser-pumped dye laser was used as an LIF probe laser. Figure 5(a) shows an example/of the temporal variation of the density of $\operatorname{CdI}\left(X^{2} \Sigma, v^{\prime \prime}=1\right)$ radicals following dissociation of $\mathrm{CdI}_{2}$. Monotonic decrease was observed even at $1.5 \mathrm{r}$ × after the photolysis laser pulse.

The concentration of $\operatorname{CdI}\left(X^{2} \Sigma\right)$ radical decayed after the very fast increase at the beginning. The decay curves were not exponential. From the reciprocal plot of the relative $\operatorname{CdI}\left(X^{2} \Sigma\right)$ radical concentration versus time as shown in Figure $5(b)$, it turned out that the concentration decay of the $\operatorname{CdI}\left(X^{2} \Sigma\right)$ radical was dominated by the second-order kinetics in our experimental conditions. This indicates that the bimolecular reaction: ${ }^{16}$

$$
\mathrm{CdI}+\mathrm{I}_{2} \longrightarrow \mathrm{CdI}_{2}+\mathrm{I}, \quad E_{0}=-88.5 \mathrm{~kJ} \mathrm{~mol}^{-1}
$$


is not important for the regeneration of $\mathrm{CdI}_{2}$. This is in contrast with the case of $\mathrm{HgBr}_{2}$, in which Erlandson and $\mathrm{Cool}^{17}$ reported that the fast bimolecular reaction:

$$
\mathrm{HgBr}+\mathrm{Br}_{2} \longrightarrow \mathrm{HgBr}_{2}+\mathrm{Br} \quad \Delta H=-113 \mathrm{~kJ} \mathrm{~mol}^{-1}
$$

was responsible for the observed rapid and efficient regeneration of $\mathrm{HgBr}_{2}$ in cyclic operation of the repetitively pulsed $\mathrm{HgBr}$ laser.

Since the observed second-order rate constant was independent of the cell pressure in the range of $0.2-1$ Torr, three-body recombination reactions can be eliminated. Possible process for the decay of $\mathrm{CdI}$ is the radical-radical disproportionation reaction:

$$
\mathrm{CdI}+\mathrm{CdI} \longrightarrow \mathrm{CdI}_{2}+\mathrm{Cd}
$$

or the abstraction reaction by the iodine atom generated,

$$
\mathrm{CdI}+\mathrm{I} \longrightarrow \mathrm{Cd}+\mathrm{I}_{2} \text {. }
$$

\section{Formation of cadmium atoms in the ground and excited states}

The energy levels of the cadmium atoms are shown in Figure 6. The ground state of $\mathrm{Cd}\left(5 s^{21} S\right)$ can be generated in the one-photon dissociation process [Eqn (3)] at $\lambda \leqslant 307 \mathrm{~nm}$, while the electronically excited states may be formed in the multiphoton dissociation of $\mathrm{CdI}_{2}$ by focusing the photolysis laser light.

\section{Formation and decay of $\operatorname{Cd}\left(5 s^{21} S\right)$}

Since the thermodynamic threshold is $307 \mathrm{~nm}$ for the production of $\mathrm{Cd}$ atoms via the process in Eqn (3), the production of Cd atoms observed at $308 \mathrm{~nm}$ must have occurred from the hot parent molecules. The $337.1-\mathrm{nm}$ irradiation gave quite a small $\mathrm{Cd}$ signal, i.e. the contribution of the following primary process is negligibly small, although it is thermodynamically possible at this wavelength. This is quite reasonable if the direct dissociation occurs from the linear structure of the parent $\mathrm{CdI}_{2}$ :

$$
\mathrm{ICdI} \longrightarrow \mathrm{Cd}+\mathrm{I}_{2} \text {. }
$$

An example of the observed signals in the 308-nm irradiation is shown in Figure 7. This signal was taken at the probe wavelength $326.1 \mathrm{~nm}$ which corresponds to the $5 s^{2}{ }^{1} S \rightarrow 5 s 5 p^{3} P$ transitions. The 


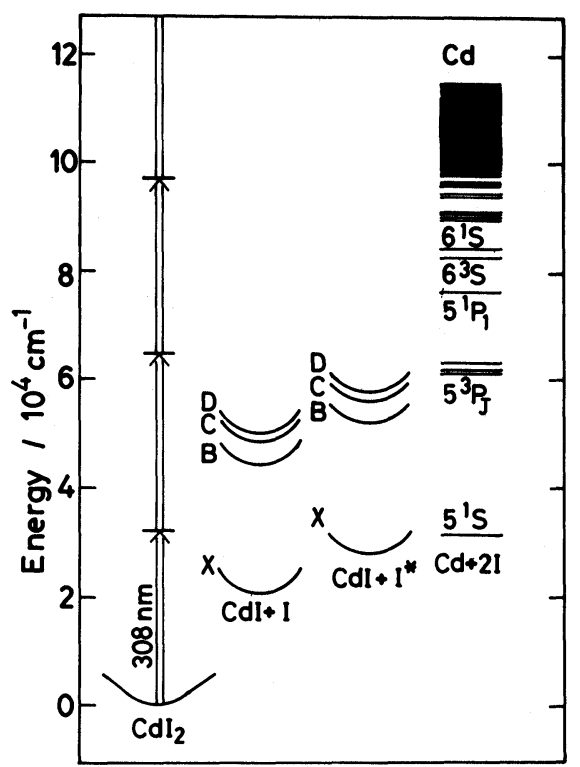

Figure 6 Energy level diagram for $\mathrm{CdI}_{2}, \mathrm{CdI}$, and $\mathrm{Cd}$. $\mathrm{I}^{*}$ refers to $\mathrm{I}\left({ }^{2} P_{1 / 2}\right)$.

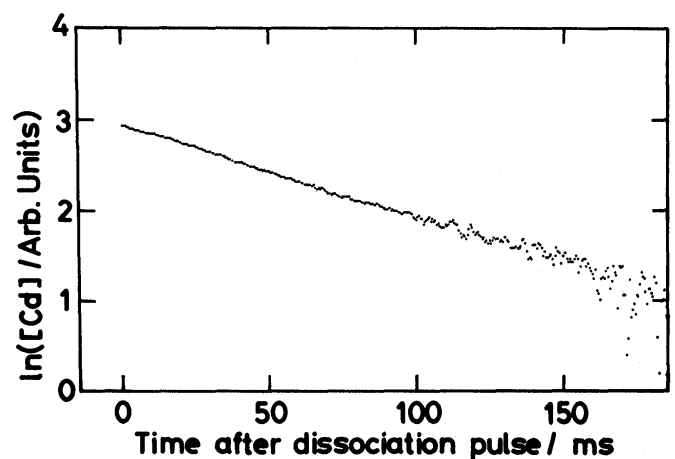

Figure 7 An example of the temporal variation of the density of $\operatorname{Cd}\left(5^{1} S\right)$ atoms following the dissociation of $\mathrm{CdI}_{2}$ with a $308-\mathrm{nm} \mathrm{XeCl}$ laser. $\lambda_{\mathrm{obs}}=326.1 \mathrm{~nm}$.

immediate rise of $\mathrm{Cd}$ signals after a laser pulse was observed within the time resolution $(\sim 100 \mathrm{~ns})$ of our instruments. This rise rate does not correspond to the decay rate of CdI radicals shown in Figure 5. This result suggests that the $\mathrm{Cd}$ atoms are directly formed in the one-photon primary process in Eqn (3), but not by the disproportionation reaction 
Table II First-order decay rates of $\mathrm{Cd}\left(5^{1} S\right)$ at various pressures of $\mathrm{CdI}_{2}$.

\begin{tabular}{ll}
\hline$P_{\mathrm{CdI}_{2}}(\text { Torr })^{\mathrm{a}}$ & $k\left(\mathrm{~s}^{-1}\right)$ \\
\hline 0.46 & 15.0 \\
0.60 & 18.0 \\
0.77 & 21.3 \\
1.05 & 28.0 \\
\hline
\end{tabular}

${ }^{\text {a }}$ Pressures are estimated from the reservoir temperatures.

of CdI radicals. The first-order decay rates obtained at four pressures of $\mathrm{CdI}_{2}$ were tabulated in Table II. Decay rates increased with the $\mathrm{CdI}_{2}$ pressure. Then, the diffusion of $\mathrm{Cd}$ atoms out of the viewing zone was not significant in the experimental conditions. Three decay modes of $\mathrm{Cd}$ atoms are to be considered:

$$
\begin{aligned}
\mathrm{Cd}+\mathrm{CdI}_{2} & \longrightarrow 2 \mathrm{CdI} \\
& \mathrm{Cd}_{2}+\mathrm{I}_{2}
\end{aligned} \quad E_{0}=90 \mathrm{~kJ} \mathrm{~mol}^{-1}
$$

Among these three, the formation of CdI radicals can be eliminated because $(a)$ it has the large heat of reaction and $(b)$ at $1.5 \mathrm{~ms}$ after the photolysis laser pulse, no increase was observed in the LIF signal of $\operatorname{CdI}\left(X^{1} \Sigma\right)$. Since the cadmium dimer is considered to be unstable in analogy to $\mathrm{Zn}_{2}{ }^{18}$ the $\mathrm{Cd}_{2}$ formation mechanism is also eliminated. Although there has been no report on CdI dimers the last process is the most plausible one. The formation of alkali halide dimers has been reported ${ }^{19}$.

\section{Formation of electronically excited $C d$ atoms}

When the photolysis laser $(308 \mathrm{~nm})$ was softly focused by a lens of $f=100 \mathrm{~mm}$, the formation of $\mathrm{Cd}\left(5 s 5 p^{3} P_{J}\right)$ was observed by means of the LIF method at $467.9 \mathrm{~nm}, 480.1 \mathrm{~nm}$, and $508.7 \mathrm{~nm}$ (Figure 8). The probe laser intensity was so strong that the saturation occurred in the pumping process from the lower ${ }^{3} P_{J}$ states to the higher $5 s 6 s^{3} S$ state. The populations of the $J=2,1$, and 0 levels were determined by the monochromatized emission intensity. The initial distribution of the $J$ states of $\operatorname{Cd}\left({ }^{3} P_{J}\right)$ determined here was almost equal for $J=2,1$, and 0 . This distribution does not fit a Boltzmann distribution at any temperature. The nascent distribution is non-statistical. 


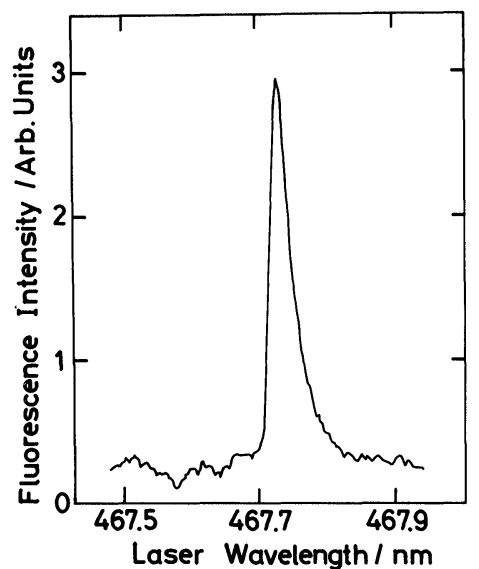

Figure 8 An example of laser-induced fluorescence spectrum of $\operatorname{Cd}\left(5^{3} P_{0}\right)$ following the dissociation of $\mathrm{CdI}_{2}$ with a $308-\mathrm{nm} \mathrm{XeCl}$ laser. $\lambda_{\mathrm{obs}}=480 \mathrm{~nm}$.

When the photolysis laser ( $308 \mathrm{~nm}$ or $337.1 \mathrm{~nm}$ ) was hard focused by a lens of $f=30 \mathrm{~mm}$, the higher electronically excited cadmium atoms $\mathrm{Cd}^{*}$ were generated as shown in the emission spectra of Figure 9. When the laser wavelength was $337.1 \mathrm{~nm}$, resonant with the transition of $\operatorname{CdI}(D-X)$, not only the atomic emission but also the $C-X$ and $B-X$ emissions of CdI were observed as shown in Figure 10. In this case, the formation mechanism of $\mathrm{Cd}^{*}$ is either the three-photon absorption of the parent molecules, or the two-photon absorption of the CdI fragments generated in the first one-photon process. However, in the 308-nm irradiation, the emission of the CdI* radicals was quite weak. The three-photon absorption of the parent molecule is obvious at this wavelength resulting in the formation of $\mathrm{Cd}^{*}$ atoms (see Figure 6):

$$
\mathrm{CdI}_{2}+3 h v \longrightarrow \mathrm{Cd}^{*}(n \geqslant 5)+2 \mathrm{I} \text {. }
$$

In order to test the formation of some specific electronic states of $\mathrm{Cd}^{*}$ in multiphoton absorption of $\mathrm{CdI}_{2}$ molecules, the $308 \mathrm{~nm}$ laser intensity was changed by a factor of 20 . The relative emission intensity ratio of $\operatorname{Cd}\left(6^{3} D_{2}\right)$ or $\operatorname{Cd}\left(5^{3} D_{2}\right)$ to $\operatorname{Cd}\left(7^{3} S_{1}\right)$ was constant. These states can be generated by the three-photon absorption. Once the parent molecule absorbs enough photon energy, the energetically possible processes seem to occur without any selectivity in the formation of the $\mathrm{Cd}^{*}$ atoms. 


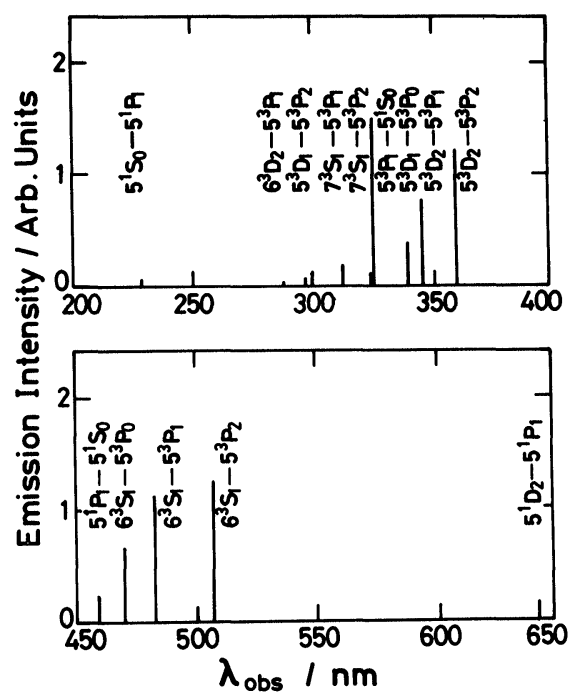

Figure 9 Emission spectra of the cadmium atom produced by the photodissociation of $\mathrm{CdI}_{2}$ with a $308-\mathrm{nm} \mathrm{XeCl}$ laser.

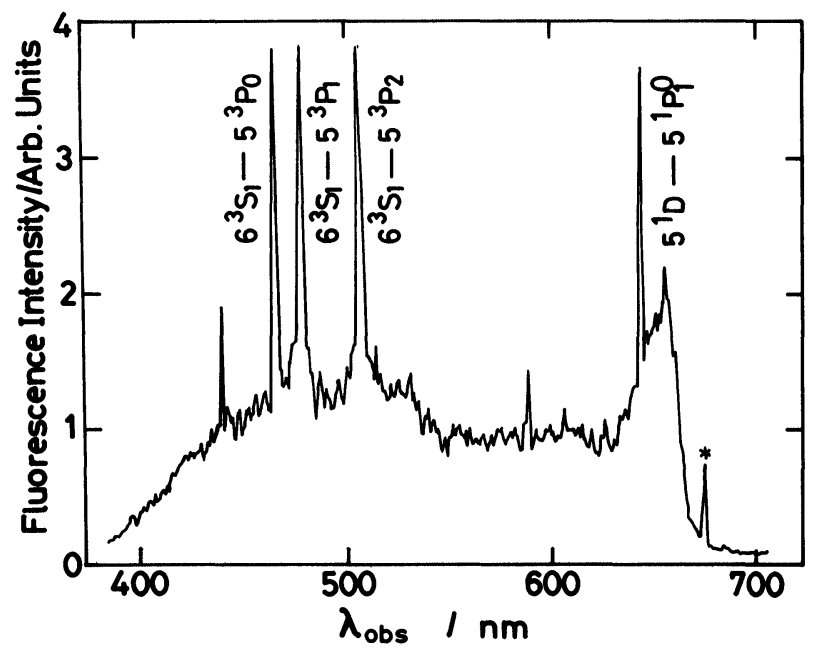

Figure 10 Emission spectra of the cadmium atom produced by the photodissociation of $\mathrm{CdI}_{2}$ with a 337.1-nm $\mathrm{N}_{2}$ laser. The peak marked by * indicates the scattered laser light. 


\section{Acknowledgements}

The authors are grateful to Messrs K. Nakane and H. Suzuki for their assistance in the experimental work. They are also grateful to the Center of Instruments, Institute for Molecular Science, Okazaki National Research Institute, for the use of the laser.

\section{References}

1. D. J. Ehrlich and R. M. Osgood Jr, IEEE J. Quant. Electron. QE-16, 257 (1980).

2. M. N. Ediger, A. W. McCown and J. E. Eden, Appl. Phys. Lett. 40, 99 (1982).

3. E. Gerk and E. Fill, IEEE J. Quant. Electron. QE-17,. 2140 (1981).

4. S. G. Dinev, H.-U. Daniel and H. Walther, Opt. Commun. 41, 117 (1982).

5. E. J. Schimitschek, J. E. Celto and J. A. Trias, Appl. Phys. Lett. 31, 608 (1977).

6. E. J. Schimitschek and J. E. Celto, Opt. Lett. 2, 64 (1978).

7. R. Bernham, Appl. Phys. Lett. 33, 156 (1978).

8. J. H. Parks, Appl. Phys. Lett. 31, 192 (1977); ibid., 31, 297 (1977).

9. W. T. Whitney, Appl. Phys. Lett. 32, 239 (1978).

10. J. G. Eden, Appl. Phys. Lett. 31, 448 (1977).

11. K. Wieland, Helv. Phys. Acta 2, 46 (1929).

12. K. G. Huber and G. Herzberg, Molecular Spectra and Molecular Structure. IV. Constants of Diatomic Molecules (Van Nostrand Reinhold, New York, 1978).

13. J. Tellinghuisen, P. C. Tellinghuisen, S. A. Davies, P. Berwanger and K. S. Viswanathan, Appl. Phys. Lett. 41, 789 (1982).

14. B. Rosen, Tables Internationales de Constantes Sélectionnées. 17. Données Spectroscopiques Relatives aux Molécules Diatomiques (Pergamon Press, Oxford, 1970).

15. M. Kawasaki, S. J. Lee and R. Bersohn, J. Chem. Phys. 71, 1235 (1979).

16. M. W. Chase, J. L. Curnutt, H. Prophet, R. A. McDonald and A. N. Syverud, JANAF Thermochemical Tables, 1975 Supplement, J. Phys. Chem. Ref. Data, 4, 1 (1975).

17. A. C. Erlandson and T. A. Cool, Chem. Phys. Lett. 96, 685 (1983).

18. M. W. McGeoch, J. Chem. Phys., 72, 140 (1980).

19. M. Blander, in Alkali Halide Vapors, eds. P. Davidovits and D. L. McFadden, eds. (Academic Press, London, 1979). 